\title{
Of snowflakes, symmetries and shells
}

\author{
The Self-Made Tapestry: Pattern \\ Formation in Nature \\ by Philip Ball \\ Oxford University Press: 1998.287 pp.

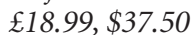

\section{Edward Cox}

One of the great and unexpected pleasures of the play Breaking the Code by Hugh Whitemore occurred when Derek Jacobi, playing Alan Turing, faced the audience and talked about spatial patterns in fir cones, and how they can be described by the Fibonacci series. When the play first opened at the Kennedy Center, my wife and I immediately bought tickets and took the train to Washington, figuring it would close after one or two performances. We were wrong. The audience was spellbound by Jacobi's soliloquies on mathematical logic, computing and pattern formation in animals and plants. The fact that Breaking the Code then went on to Broadway and enjoyed great success is still a bit of a puzzle - are there really enough biologists and mathematicians around to sustain a good Broadway run?

Part of the key to understanding the play's success, I think, lies in everyone's interest in the origins of symmetries and patterns in nature. It may even be that our visual system, with its remarkable abilities as a pattern detector, is at the root of this interest. It goes quite deep in another sense too, a need to discover first causes. We look for patterns in space and time, of course, but we also try to understand where they come from - how radial symmetries emerge from a spherical egg, why honeycombs are hexagonal, how radiolarians create beautifully patterned exoskeletons, how snowflakes form, the universal patterns apparent in mountainscapes and why soap bubbles pack the way they do.

In his new book, Philip Ball talks about these questions at engaging length and with a balance, thoroughness and simplicity that I found remarkable. In ten chapters he moves from bubble and foam structure, subjects that can be understood by appeal to simple geometry and physics, to travelling and standing waves used by living systems to set up coordinates, and then on to fluid dynamics, community ecology, and finally a chapter on physical principles, the best introductory chapter on this subject I have read.

In a sense, the first part of the book is divided into topics inspired by D'Arcy Thompson's On Growth and Form and by Turing's remarkable paper, "The chemical basis of morphogenesis". Although both authors searched for physical explanations, Thompson's took the form of mathematical description and mechanical principle, while for Turing the language of mathematics was

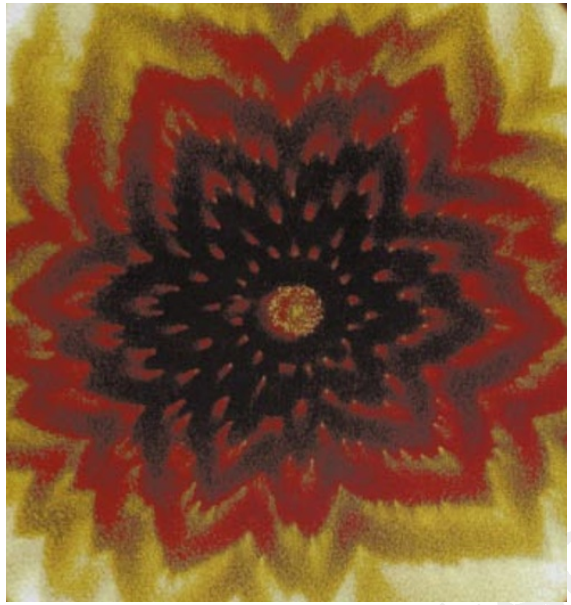

In formation: "self-made" patterns induced in a bacterial colony by chemotaxis.

used to describe the emergence of patterns from apparently featureless initial conditions. Later in the book, Ball turns to contemporary discussions of branching patterns (snowflakes, crack propagation in solids, viscous fingering, diffusion-limited aggregation), fluid flow, sand-piles and self-organized criticality.

There are very few patterns in biology, physics and chemistry that Ball fails to examine carefully, illustrating along the way principles of self-organization and thermodynamics that work at all levels and length scales. There are particularly fine expositions of bubble and foam structure, which he introduces by discussing D'Arcy Thompson's views on honeycomb symmetries.

Ball's style is historical and comparative, illustrating the twists and turns that lead from observation to understanding. This makes for fascinating reading — just when I thought I understood why bees are such excellent geometers, I was given a new insight which, it turned out, also had its problems. Perhaps the true explanation has now arrived with the work of D. Weaire and R. Phelan on bubble packing (Nature 367, 123; 1994).

Ball describes the essential features of Turing's contribution to the genesis of spatial patterns, which has proved to be a very rich source of ideas in chemistry and biology, illustrating by example how local autocatalysis and long-range inhibition can yield such amazing variety. His examples are all aptly chosen: from biology we have sea-shell and animal coat patterns, the eyespots on butterfly wings, spiral waves in Dictyostelium territories and chemotaxing bacteria on agar surfaces; and from physics, wave propagation on catalytic surfaces, Liesegang rings in tubes and flow patterns in cylindrical flames. He gives the reader a good feeling for why order can emerge from these disparate systems, which vary enormously in scale and physical mechanism.

At times the going is tough. The Belousov-Zhabotinsky reaction can finally only be understood by quantitative arguments, I think. No amount of appeal to metaphor seems to work really well. Still, as one who has failed many times at teaching this reaction, I sympathize, and see this as a generic problem when discussing complex systems. When all is said and done, in some systems and circumstances, the interested reader must model complexity by coming to grips with the mathematics of the system. Still, it is remarkable, I think, that Ball manages more often than not to do so well without formal arguments.

Many authors who cover grand and complicated topics do so by sacrificing accuracy in their search for simple language. Ball's approach is to write carefully, be sceptical and non-polemical about data and their interpretation, and give credit to heterodox views where credit is due. In sum, he is critical of the literature and its interpretation, perhaps, as he says in the introduction, because his "years at Nature magazine have exposed me to too many amazing discoveries that vanish like morning mist under close scrutiny".

Since the appeal of patterns in nature has such a strong aesthetic component, it is a pleasure to report that this book is handsomely and accurately printed and produced. It contains many wonderful illustrations, both in colour and in black and white, and very few errors, factual or typographical.

Edward Cox is in the Department of Molecular

Biology, Princeton University, Princeton,

New Jersey 08544, USA.

\section{Life, the Universe and the single mollusc}

\section{Civilization and the Limpet}

by Martin Wells

Perseus Books: 1998. 224 pp. \$22, £15.50

\section{JohnShepherd}

Do you know the link between the sexual habits of the slipper limpet and a Roman aqueduct? Or why slipper limpets are sufficiently remarkable to be favoured with the specific name Crepidula fornicata? Have you ever wondered how ordinary limpets find their way home after a busy day cleaning algae off the rocks? Do you know the best way to catch an octopus? Or why whales don't get the bends? The answers to these and many other intriguing questions can be found in this 


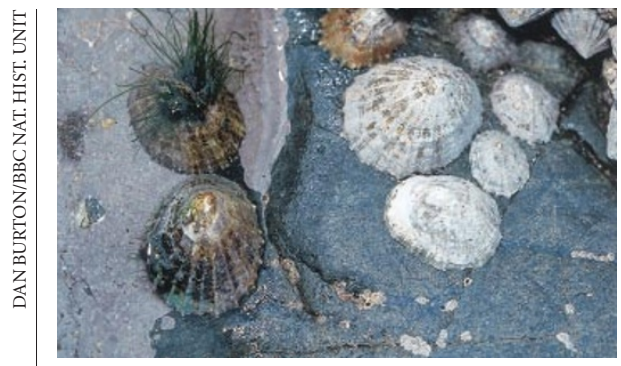

Safely grazing: limpets' navigational powers will help them to find their way home.

engagingly haphazard collection of essays.

The author, Martin Wells, is a marine biologist, an expert on cephalopods and a yachtsman. He originally conceived the book as a journal of a voyage, but his enthusiasm for his subject has led him astray, and we can be grateful for that. Life is, after all, what happens to you while you are making other plans. Each essay is based on some aspect of the life of an animal in the sea, but develops fugue-like to encompass observations on life, the Universe and even, as the title promises, civilization. The tone is set, and Wells's philosophy of life begins to beguile, on the very first page of his preface, when he remarks that "some poor people work for all their lives, and all they ever make is money".

He develops his discussion on the navigational powers oflimpets - through a discursion on the perceptual powers of octopuses in two and three dimensions - to explain how these are affected by the limpets' lack of bones and joints. And thence to the ability of vertebrates to build cars and computers, and to bash the ozone layer. In a similar vein, one chapter begins with an uncle who was interested in lugworms and defaecation, and develops into a discussion of biological clocks and free will. A comment on the sheltered life led by physicists, and its limiting effect on their powers of imagination, leads via the effects of entropy (and how to contain them using a can of WD-40) to your chances of surviving the next mass extinction.

Wells's own speciality gets its share of the action, too, with accounts of the swimming and depth-control abilities of squid, and the locomotive and reproductive adaptations of Nautilus, its ability to tolerate low oxygen levels, and how this may be relevant to the success of ammonites in the remote past. In a final chapter, "Does science have to be useful?", he mounts a spirited attack on the utilitarian orthodoxy of our time, asserting the claim of science (like the arts) to be supported not least because it amuses, entertains and enriches our lives. Along the way he claims that biologists are more realistic than 'hard' scientists in their judgements because they are used to dealing with the messiness of the natural world. I think physicists working as meteorologists, among others, may disagree with that.

My only complaint is that there are no illustrations to add further spice to this rich mixture. If you need an antidote to the world of targets, objectives, milestones and deliverables, I heartily recommend this book. A scientist who is willing to say that his studies of Nautilus give him an excuse "to swan off to the Pacific, and there spend a quite unnecessary proportion of my time underwater" should be cherished, for this is not politically correct, and such a scientist may become an endangered species. Read this and recapture the pleasure of mucking about in rock pools, just for fun. But spare a thought for the limpet, because "a limpet has nothing, or next to nothing, to fantasize about".

John Shepherd is at the Southampton

Oceanography Centre, University of Southampton, Empress Dock, Southampton SO14 3ZH, UK.

\section{Africa's mistletoes ripe for the picking}

\section{Mistletoes of Africa}

by Roger Polhill and Delbert Wiens

Royal Botanic Gardens, Kew: 1998.

370 pp. $£ 70$

\section{Jeremy Midgley}

Mistletoes are rootless plants that plug into the 'plumbing' of their host plant's stem to steal water, dissolved minerals and, to varying degrees, organic products. They are a unique yet global group, full of fascinating attributes. But until now there has been no comprehensive book on the African species. Roger Polhill and Delbert Wiens' Mistletoes of Africa gives an up-to-date summary of mistletoe biology, keys to the taxa and some biogeography, as well as describing their haustoria (by which they attach to the host) and flower structure in relation to opening, and providing appetizers for further work, for which they note a strong need.

Mistletoes may be in danger of extinction for several reasons. They are probably prone to excessive herbivory by large African animals like elephants. It has even been suggested that the absence of large animals, such as giraffe, in some reserves leads to a build up of mistletoes on their preferred hosts, thorny acacias. This increase in mistletoes attracts fruit-eating birds which in turn produces an influx of seeds of fleshy-fruited, broad-leaf species that become established beneath the acacia. Eventually, acacia savanna is replaced by dense, broad-leaf woodlands, the phenomenon of bush encroachment. This is perhaps an exaggeration but certainly more work is needed on the relationships between large African mammals and mistletoes.

Some mistletoes may be vulnerable because of their obligate relationships with mutualists. Dioecious fleshy-fruited species, like Viscum continuum, depend on animals for both pollination and dispersal. People are also potentially disastrous for mistletoes. 'Wood roses', shaped from haustoria of savanna mistletoes, are common in the curio markets of South Africa. They are carved from mistletoes that can be more than 50 years old; excessive use may not be sustainable.

A largely African aspect of mistletoe ecology is their occurrence on succulents, where some ramify within the tissues of their hosts. They reach their most advanced and reduced stage in $V$. minimum of the eastern Cape, a really weird plant. Its shoot (less than 3 millimetres long, see below) is far smaller than the berry it produces; in fact, the whole plant looks like its host plant's fruit.

Non-endophytic mistletoes are almost globally restricted to arid regions of Africa and their physiology is intriguing. We do not know whether they use the stored water or the xylem stream of their host plant. Mistletoes open their stomata and fix carbon during the day; succulents, on the other hand, open their stomata at night - an uneasy relationship. Further physiological pieces of this fascinating jigsaw are needed.

Host relations also need research. Polhill and Wiens suggest, for example, that host specialization is more frequent when potential host diversity is low. Some species are even restricted to parasitizing other mistletoes (for example, the epiparasitism of $V$. goetzii and V. loranthicola). Others are single dots on the African map, such as V. grandicaule, the largest Viscum, which only grows on fig trees on the island of Pagalu, off Gabon.

African mistletoes are similar to those found elsewhere in the world as well as having many unique characteristics. With the publication of this book, work on African mistletoes can now safely enter an "after-description phase".

Jeremy Midgley is in the Botany Department, University of Cape Town, P Bag Rondebosch, 7701 South Africa. 